\title{
The Effects of Seed Priming with L-glutamine and L-arginine Amino Acids in Pepper Seeds
}

\author{
Elena BARCANU ${ }^{1 *}$, Konstantinos PASCHALIDIS ${ }^{2}$, Costel VÎNĂTORU ${ }^{1}$, Ovidia DOBRE (AGAPIE) ${ }^{1}$, Ion \\ GHERASE$^{1}$, Bianca TĂNASE ${ }^{1}$, Geanina NEGOȘANU ${ }^{1}$ and Elena DRĂGHICI ${ }^{3}$ \\ ${ }^{1}$ Vegetable Research-Development Station Buzau, 23 Mesteacanului St, Romania \\ ${ }^{2}$ School of Agricultural and Food Technology, Stavromenos, Heraklion, Crete, Greece \\ ${ }^{3}$ Faculty of Horticulture, University of Agronomic Science and Veterinary Medicine of Bucharest, 59 \\ Marasti Boulevard, Romania \\ * corresponding author: barcanuelena@yahoo.com
}

BulletinUASVM Horticulture 77(2) / 2020

Print ISSN 1843-5254, Electronic ISSN 1843-5394

DOI:10.15835/buasvmcn-hort: 2020.0040

\begin{abstract}
Seed-priming is a physiological technique of seed hydration and drying to enhance the germination. Seed priming treatments can be used to achieve even and earlier sprouts. A popular seed-priming practice which helps the seeds germinate faster is hydro-priming. Other studies have shown that seed priming with $\alpha$-arginine promotes growth in sunflower. Pepper seeds germinate slowly and the aim of this study was to assess the effects of seed priming with $\alpha$-glutamine and $\alpha$-arginine amino acids in pepper seeds grown in different fertilization scheme. During the evaluation it can be concluded that seed-priming treatment with $\alpha$-arginine and double distilled water speeds up the sprouting. At some variants, it was proven that $\alpha$-glutamine seed-priming was inefficient. It was also found that fertilization schemes influence the germination and root growth in the following year.
\end{abstract}

Keywords: Capsicum annuum, fertilization scheme, sprouting

\section{Introduction}

Capsicum annuum L. seeds are one of the vegetable species from Solanaceae family that germinates slowly. Seed-priming is a physiological technique of seed hydration and drying to enhance the pregerminative metabolic process for a good germination. Taylor et al. (1998) states that this prevents the seeds from absorbing enough water for radicle protrusion, thus suspending the seeds in the lag phase. Seed priming has been commonly used to reduce the time between seed sowing and seedling emergence and to synchronize emergence (Parera and Cantliffe, 1994). A popular seed-priming practice which helps the seeds germinate faster is hydro-priming. This technique helps the seed to imbibe water and go through the first phase of germination in which pre-germination metabolic activities are started while the latter two phases of germination are inhibited (Pill and Necker, 2001). Other studies have shown that seed priming with $\alpha$-arginine promotes growth in sunflower (Nejadalimoradi et al., 2014) or bean plants (Zeid, 2009). Liu et al. (2006) state that $\alpha$-arginine is one of the most functionally diverse amino acids and a precursor for polyamine biosynthesis. Polyamines modulate several biological processes in plants, including cell division, differentiation, and senescence and it has been suggested that they participate in cellular defense against oxidative damage through the inhibition of lipid peroxidation and scavenge of free radicals (Velikova et al., 2000). L-glutamine is good nitrogen source, which cells need to grow well and quickly. Some studies (Pop et.al, 2014) suggests that the use of A.D. type bio-phyto- 
modulators accelerates the plant sprouting in tomato and peppers seeds.

\section{Materials and methods}

In this study, the biological material used was represented by two new cultivars of peppers obtained at Vegetable Research Development Station Buzau ('Regal', 'Cantemir' noted with L3 and L70) grown in five fertilization schemes. The experimental variants used are presented in Table1.

The seeds obtained were conditioned, analyzed and were subjected to seed-priming treatments. For seed-priming it was used: (V1) solution of $1 \mathrm{mM}$ of $\alpha$-arginine, (V2) $1 \mathrm{mM}$ of $\alpha$-glutamine, (V3) a mix of $1 \mathrm{mM}$ of $\alpha$-arginine with
$1 \mathrm{mM} \alpha$-glutamine and (V4) a control variant with double distilled water. The seeds were primed for 24 hours. After priming, the seed were grown in Petri dishes, with added $10 \mathrm{ml}$ of water every time needed, in a control temperature room at $25^{\circ} \mathrm{C}$. The samples were made in triplicate. To preserve a sterile environment, all samples were process in a biological safety hood Telstar Bio II with UV filter.

\section{Results and discussions}

Throughout the research, it was observed that in the experiment with $\alpha$-arginine, the seeds have begun to sprout first at L70V4, followed by L70V2, but at the end of the sprouting process, the best result with $100 \%$ germinated seeds were recorded by variants L3V3 and L70V3. The

Table 1. List of fertilizers used in the experiment

\begin{tabular}{ccc}
\hline Variant & Fertilizer & Compositions \\
\hline \multirow{2}{*}{ V1 } & $\begin{array}{c}\text { Organic }- \text { a mix of two } \mathrm{N}(3 \%), \mathrm{Cu}(2.5 \%), \mathrm{Na}(0.05 \%), \text { Organic matter (1.5\%) Diuresis }(0.04 \%) \\
\text { types of fertilizers }\end{array}$ & $\mathrm{N}(17 \%), \mathrm{K}(1.5 \%)$, Organic matter (3.2\%), Diuresis $(0.26 \%)$ \\
\hline \multirow{2}{*}{ V2 } & Organic & Organic matter (70\%), $\mathrm{N}$ total (3\%), $\mathrm{N}$ organic $(2.8 \%), \mathrm{P}_{2} \mathrm{O}_{5}(3 \%), \mathrm{K} \mathrm{O}$ \\
& Organic & $\mathrm{N}$ total $(8 \%), \mathrm{Kg}(1.3 \%), \mathrm{Ca}(26 \%), \mathrm{Na}(0.2 \%)$ \\
\hline V3 & Chemical & $\mathrm{N} \mathrm{(6 \% )} \mathrm{P}_{2} \mathrm{O}_{5}(12 \%) \mathrm{K}_{2} \mathrm{O}(24 \%), \mathrm{B}, \mathrm{Cu}, \mathrm{Fe}, \mathrm{Mn}, \mathrm{Zn}, \mathrm{Mo}$ \\
\hline V4 & Control variant & No fertilizers used \\
\hline V5 & &
\end{tabular}

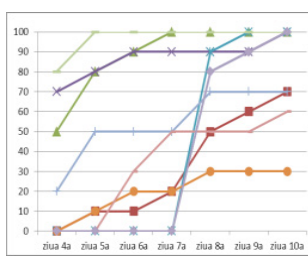

\begin{tabular}{|c|c|}
\hline$\rightarrow 13 n_{1}$ & \\
\hline-1312 & 80 \\
\hline$\leftarrow 13 \sqrt{3}$ & \\
\hline -1354 & 60 \\
\hline $\begin{array}{l}-1315 \\
\rightarrow-10011\end{array}$ & $\begin{array}{l}50 \\
40\end{array}$ \\
\hline -trove & \\
\hline \begin{tabular}{c|c} 
- & 20003 \\
-10004 & 2
\end{tabular} & 20 \\
\hline$\rightarrow$ Lovvs & \\
\hline
\end{tabular}

Figure 1. Germination percentage using $\alpha$-arginine solution

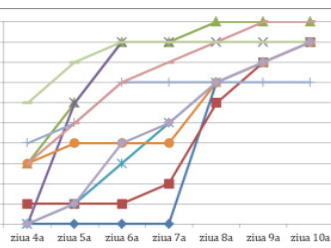

Figure 2. Germination percentage using $\alpha$-glutamine solution

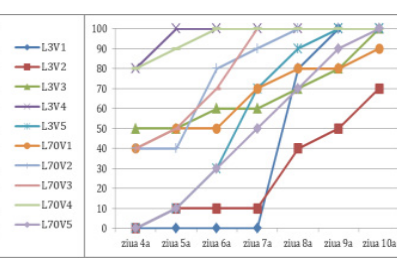

Figure 3. Germination percentage using $\alpha$-glutamine and $\alpha$-arginine solution

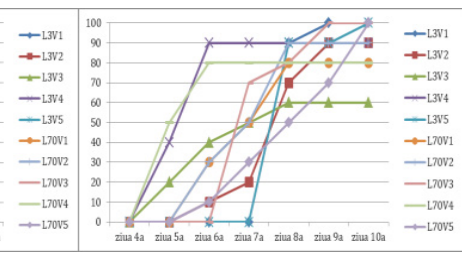

Figure 4. Germination percentage using double distilled water

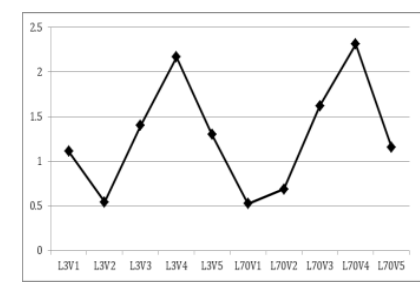

Figure 5. Variation of radicle length using $\alpha$-arginine solution

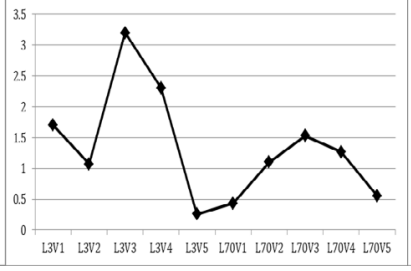

Figure 6. Variation of radicle length using $\alpha$-glutamine solution

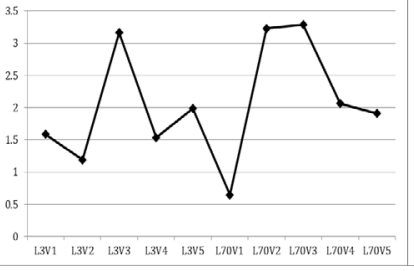

Figure 7. Variation of radicle length using $\alpha$ glutamine and $\alpha$-arginine solution

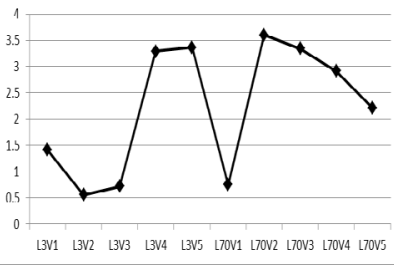

Figure 8. Variation of radicle length using double distilled water 
variants L3V4 and L70V4 with double distilled water have sprouted completely after six days, with a germination percentage of $100 \%$. After ten days, just variants L3V2 and L70V1 had a germination of $70 \%$ and the rest of variants sprouted $100 \%$. The germination percentage and variation of radicel length is presented in Figures 1-8.

The experimental variants with $\alpha$-glutamine and mix of $\alpha$-arginine and $\alpha$-glutamine solution emerged after 5 days from sowing, and after 10 days, only five variants (L3V3, L3V4, L3V5, L70V4, L70V5) germinated over $90 \%$, respectively six variants (L3V1, L3V4, L70V1, L70V3, L70V4) in the case of $\alpha$-arginine and $\alpha$-glutamine solution. The root had weak growths, managing only in the case of L3V4 to be over $2 \mathrm{~cm}$ long. As a summary, in some variants the seed-primming treatment is efficient, while with others it proves to be fruitless.

It can be concluded, that the experimental variants with sprouting percentage of over $90 \%$, but also with the highest root growth (over $3 \mathrm{~cm}$ ) were recorded by the solution with $\alpha$-arginine and double distilled water.

The percentage of sprouting differed depending on the fertilization scheme, the best result being recorded by L70V3 and L3V4. At the opposite pole, the fertilization variants with the weakest radicle growths were the control variants, L3V5 and L70V5, but also L70V1. In the essence, the fertilization scheme has an influence on the germination process in the following year and the choice of a balanced fertilization scheme is important for the future crop.

Other studies suggests that seeds physiological quality is influenced by pre-harvesting conditions, by the harvesting and post-harvesting practices, as well by the storage conditions (de Mattos and de Carvalho, 2016; Sano et al., 2016; Singkaew et al., 2017). In order to establish a good germination of further crops it is important to have a balanced fertilization scheme during the vegetation period, an optimal time for seed harvesting, good pre-harvesting and post-harvesting practice, an adequate storage conditions and a suitable seed-priming technique, followed, of course, by a flawless growing room.

\section{Conclusions}

In the present work, it was shown that seedpriming with $\alpha$-arginine and double distilled water speeds up the sprouting process and promo- tes root development in early stages of vegetation. At some variants, it was proven that $\alpha$-glutamine seed-priming was inefficient. It was also found that fertilization schemes influence the germination and root growth in the following year.

Acknowledgments. This work was supported by one founding source a grant of the Romanian Ministry of Research and Innovation, CCCDI - UEFISCDI, project number PN-III-P1-1.2PCCDI-2017-0850/ contract 14 PCCDI /2018, within PNCDI III.

\section{References}

1. De Mattos C, De Carvalho TC (2016). Comparative study of tomato seeds physiological quality hybrid and creole. Applied Research \& Agrotechnology, 9 (2): 45-52.

2. Liu JH, Nada K, Honda C, Kitashiba H, Wen XP (2006). Polyamine biosynthesis of apple callus under salt stress. Importance of the arginine decarboxylase pathway in stress responses. Journal of Experimental Botany. 57: 2589-2599.

3. Havva N, Nasibi F, Kalantari KM, Roya Z (2014). Effect of seed priming with L-arginine and sodium nitroprusside on some physiological parameters and antioxidant enzymes of sunflower plants exposed to salt stress. Agric Commun, 2(1): 23-30

4. Parera AC, Cantliffe DJ (1994). Pre-sowing seed priming. Hortic. Rev. 16109-148.

5. Pill WG, Necker AD (2001). The effects of seed treatments on germination and establishment of Kentucky bluegrass (Poapratense L.). Seed Sci.Technol. 29: 65-72.

6. Pop FM., Criveanu HR, Inoan SL (2014). The Influence of Bio-Phyto-Modulators in the Biological Development of Seed Germination in Tomato and Pepper Plants. Bulletin of University of Agricultural Sciences and Veterinary Medicine Cluj-Napoca. Horticulture, 71(1): 71-73.

7. Sano N, Rajjou L, North HM, Debeaujon I, Marion-Poll A, Seo M (2016). https://academic.oup.com/pcp/issue/57/4 Staying Alive: Molecular Aspects of Seed Longevity. Plant and Cell Physiology, 57: 660-674.

8. Singkaew J, Miyagawa S, Wongs-Aree C, Vichitsoonthonkul T, Sokaokha S, Photchanachai S (2017). Season, Fruit Maturity, and Storage Affect on the Physiological Quality of F1 Hybrid 'VTM580' Tomato Seeds and Seedlings. The Horticulture Journal, 86: 121-131.

9. Taylor AG, Allen PS, Bennett MA, Bradford KJ, Burrisand JS, Misra MK (1998). Seed enhancements. Seed Sci. Res. 8: $245-256$

10. Velikova V, Yordanov I, Edreva A (2000). Oxidative stress and some antioxidant systems in acid rain-treated bean plants. Protective role of exogenous polyamines. Journal of Plant Science. 151: 59-66.

11. Zeid IM (2009). Effect of arginine and urea on polyamines content and growth of bean under salinity stress. Journal of Acta Physiologiae Plantarum. 31: 65-70. 